TecnoHumanismo. Revista Científica

Setiembre - Noviembre 2021

Volumen 1 / No.3

ISSN: $2710-2394$

pp.437-456

https://doi.org/10.53673/th.v1i11.76

https://tecnohumanismo.online

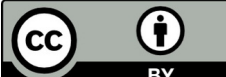

\title{
Derrotabilidad de la norma (reglas y principios) y constitución
}

Defeasibility of the norm (rules and principles) and constitution

Revogabilidade da norma (regras e princípios) e constituição

\section{ARTÍCULO GENERAL}

\section{Iván Paul Herrera Salazar \\ ivanhs_04al@hotmail.com \\ https://orcid.org/0000-0002-1850-8385 \\ Investigador Independiente, Lima - Perú}

Recibido 07 de Abril 2021 | Arbitrado y aceptado 19 de Junio 2021 | Publicado en 03 Setiembre 2021

\section{RESUMEN}

El objetivo del artículo fue determinar la relación jurídica entre derrotabilidad de la norma y Constitución. Para ello, se llevó a cabo un abordamiento desde tres enfoques jurídicos configurados en dimensiones jurídicas (dogmático jurídico, socio jurídica y axiológica). En este orden, el punto de vista teórico consideró la teoría de los deberes prima facie, la distinción entre reglas y principios y la incompleta formulación de los conceptos jurídicos. Desde el enfoque socio jurídico se centró en el análisis de tres fallos (sentencia del Tribunal judicial constitucional federal alemán, 1996; sentencia del Tribunal Constitucional, 2003; y, diversas sentencias del Tribunal Constitucional peruano. Para el enfoque axiológico, se adoptaron tres indicadores (los principios generales del derecho, instrumentos internacionales y el principio de dignidad humana). Como contraparte, la Constitución fue examinada como norma, jurisprudencia y doctrina. Metodológicamente, se tomaron como muestra 60 trabajos de carácter académico y 10 jurisprudencias de origen nacional internacional y supraconstitucional; además, una muestra de especialistas en Teoría General del Derecho constitucional. Se aplicaron las técnicas de revisión documental y entrevista abierta semi estructurada dirigida a expertos. Se concluyó que existe relación jurídica entre derrotabilidad de la norma y Constitución desde tres enfoques de investigación jurídica.

Palabras clave: Teoría de la Incompleta formulación de los conceptos jurídicos, Teoría de los deberes prima facie de Ross, distinción entre reglas y principios, jurisprudencia, Instrumentos internacionales sobre derechos humanos y principio de dignidad.

\section{ABSTRACT}

The objective of the article was to determine the legal relationship between the defeasibility of the norm and the Constitution. For this, an approach was carried out from three legal approaches configured in legal dimensions (legal dogmatic, socio-legal and axiological). In this order, the theoretical point of view considered the prima facie theory of duties, the distinction between rules and principles, and the incomplete formulation of legal concepts. From the socio-legal approach, he focused on the analysis of three judgments (judgment of the German Federal Constitutional Court, 1996; judgment of the Constitutional Court, 2003; and various judgments of the Peruvian Constitutional Court. For the axiological approach, three indicators were adopted ( the general principles of law, international instruments and the principle of human dignity). As a counterpart, the Constitution was examined as a norm, jurisprudence and doctrine. Methodologically, 60 academic papers and 10 jurisprudences of national international and supra-constitutional origin were taken as a sample. In addition, a sample of specialists in the General Theory of Constitutional Law. The techniques of documentary review and semi-structured open interview directed to experts were applied. It was concluded that there is a legal relationship between the defeasibility of the norm and the Constitution from three legal research approaches.

Keywords: Theory of Incomplete formulation of legal concepts, Ross's prima facie theory of duties, distinction between rules and principles, jurisprudence, International instruments on human rights and the principle of dignity.

\section{RESUMO}

O objetivo do artigo era determinar a relação jurídica entre a revogabilidade da norma e a Constituição. Para tanto, foi realizada uma abordagem a partir de três enfoques jurídicos configurados nas dimensões jurídicas (jurídico dogmático, sócio-jurídico e axiológico). Nessa ordem, o ponto de vista teórico considerou a teoria prima facie dos deveres, a distinção entre regras e princípios e a formulação incompleta dos conceitos jurídicos. Do ponto de vista sócio-jurídico, ele se concentrou na análise de três sentenças (sentença do Tribunal Constitucional Federal Alemão, 1996; sentença do Tribunal Constitucional, 2003; e vários acórdãos do Tribunal Constitucional Peruano. Para o enfoque axiológico, três indicadores foram adotados (os princípios gerais de direito, os instrumentos internacionais e o princípio da dignidade humana). Em contrapartida, a Constituição foi examinada como norma, jurisprudência e doutrina. Metodologicamente, 60 trabalhos acadêmicos e 10 jurisprudências de âmbito nacional internacional e supraconstitucional retirou-se como amostra a origem, e também uma amostra de especialistas da Teoria Geral do Direito Constitucional. Foram aplicadas as técnicas de revisão documental e entrevista aberta semiestruturada dirigida a especialistas. Concluiu-se que existe uma relação jurídica entre os inviabilidade da norma e da Constituição a partir de três abordagens de pesquisa jurídica.

Palavras-chave: Teoria da formulação incompleta de conceitos jurídicos, teoria prima facie dos deveres de Ross, distinção entre regras e princípios, jurisprudência, instrumentos internacionais sobre direitos humanos e o princípio da dignidade. 


\section{Introducción}

Del entramado de relaciones entre derrotabilidad de la norma y Constitución surge una contradicción problemática analizable desde tres direcciones investigativas. Primera, si una norma expresa un contenido aproximadamente compatible con el valor axiológico esencial formalizado, a la sazón, es válida, no obstante, su condición de derrotabilidad. Bustamante (2019) insistió en que si las normas, grosso modo, son antinómicas, significa que la de más alta jerarquía, ulterior temporalmente o de mayor especialidad predomina, sin embargo, su condición de derrotabilidad (Rodríguez, 2018). Por otro lado, se tiene que una norma derrotable puede inaplicarse respecto de una cuestión subsumible dentro de su radio de acción, sin que por ello cese su aplicabilidad ante a otras cuestiones igualmente subsumibles. Esto no significa que haya tocado su validez. (Pazos, 2002). Lo descrito presenta problemas. Si bien el enfoque dogmático jurídico presenta elementos integradores para un concepto, la doctrina carece de una que sintetice el debate. Así, la derrotabilidad se confunde con invalidez e inaplicación (Ramírez, 2019). Por ello, se cuestiona si toda disposición derrotada es una inválida o inaplicable. (García, 2003).

La ausencia de una definición que sirva de síntesis ante las variantes de conceptos planteados dentro de la dogmática jurídica deriva en confusión, de tal modo que en ocasiones se utilizan los términos derrotabilidad, validez e inaplicación de modo arbitrario (Alegre, 2017). Por ello, surge la necesidad de aportar una solución teórica con triple propósito: la elaboración de una síntesis de la noción de derrotabilidad desde la teoría de la Incompleta formulación de los conceptos jurídicos, desarrollada por Hart (1961), la teoría de los deberes prima facie de Ross (1994), desarrollada por Caballero (2017) y la distinción entre reglas y principios (Bäcker, 2014), ampliamente desarrollada por Etcheverry (2020), desde la teoría general del Derecho (Noguera, 2020); luego, la producción de una correcta diferenciación lógico jurídica respecto de la validez (Arango \& Herazo, 2020).; finalmente, la elaboración de una adecuada distinción entre derrotabilidad invalidez e inaplicación de la norma (Rodríguez, 2015). Este planteo presenta problemas de gran dimensión desde la Constitución política del Estado.

Segunda, desde una óptica socio jurídica la derrotabilidad de la norma presenta una práctica jurisprudencial donde la regla de la derrotabilidad genera una contradicción entre juridicidad y jurisdicción constitucionales (Orozco, 2020). En efecto, una regla (con características de validez abstracta - semánticamente y de estructuralmente consumada) es inaplicada (Cristiano, 2017). Alexy, (2000) indicó que el Tribunal Constitucional Federal alemán falló en 1996 la validez constitucional de sentencias penales que castigaban por homicidio causado por sucesos acontecidos en 1984. Para el Derecho aplicable, en ese espacio temporal los hechos no representaban una conducta típica y antijurídica lo cual contravino el $103^{\circ} 2$ de la Ley Fundamental de Bonn que prohibía la figura de irretroactividad maligna de la ley penal sin excepciones. (Mira, 2017). Otro ejemplo fue el Tribunal Constitucional español cuando en 2003 so pretexto de defensa del derecho a la libertad de información favoreció la propagación de pormenores personales de una causa judicial que aún no arribaba a la fase de juicio oral (Fernández, 2019). No obstante, el artículo $301^{\circ}$ de la Ley de Enjuiciamiento Criminal española, exigía el secreto de las diligencias sumarias hasta la etapa del juicio oral. (Rodríguez, 2014). 
Las causas de este fenómeno se encuentran en precaria formación ideológica democrática y constitucional tanto de la sociedad civil como de la institucionalidad. En efecto, la falta de reacción institucional frente a este fenómeno trae como consecuencia que el Derecho en la práctica histórico social en muchas ocasiones no sea vinculante para la jurisdicción constitucional, o que los veredictos de esta obedezcan a un criterio arbitrario y anárquico o que tal insujeción sea avalada por el poder estatal y la sociedad.

Tercero, desde una óptica axiológica, se presenta filosóficamente la inderrotabilidad del derecho a la dignidad humana (Estay, 2019). Efectivamente, el concepto de Estado constitucional de Derecho ha traído consigo un conjunto de desarrollos valorativos que han terminado colocando al ser humano y su dignidad como fines del Estado y la sociedad. Esto implica que hay un determinado ligado de derechos que desde un punto de vista valorativo no están sujetos a derrota (Rodríguez, 2015), pues esta implicaría un retroceso hacia modelos premodernos autoritarios y absolutistas. No obstante, en el Derecho hay figuras jurídicas que contravienen derechos fundamentales de carácter inderrotable. Por ejemplo, cadena perpetua, prohibición de beneficios penitenciarios o testigos con clave secreta que cuestionan el objeto constitucional del régimen penitenciario vinculado con la reeducación, rehabilitación y reincorporación del penado a la sociedad o el debido proceso, el derecho de defensa, el derecho de contradicción, entre otros. De este modo, el concepto axiológico de derrotabilidad suele estar de cabeza por reglas (como la seguridad ciudadana, bajo un discurso de emergencia penal) que derrotan principios que gozan de reconocimiento de toda la comunidad internacional y que se relacionan con un tinglado de derechos que nacen desde el principio de dignidad humana cuya esencia debe ser protegida como fin supremo del Estado y la sociedad.

En suma, hay un problema de definición de derrotabilidad que logre sintetizar desde la teoría general del Derecho el concepto mediante tres aspectos: la Incompleta formulación de los conceptos jurídicos, los deberes priman facie y, la distinción entre reglas y principios. Esta definición debe derivar en una diferenciación lógico-jurídica de la derrotabilidad respecto de la validez y la inaplicación. Desde una perspectiva socio jurídica se presenta un problema de práctica jurisprudencial debido a que determinadas cortes constitucionales inaplican reglas (lógicamente válidas y estructuralmente logradas) sin que existan dentro del su marco, excepciones explícitas o explícitas. Desde una perspectiva axiológico-jurídica, la derrotabilidad se ha invertido de tal modo que se ponderan reglas por encima de principios: se prefiere el derecho positivo y sus características de utilitarismo y eficientismo social frente a derechos que constituyen el eje y centro de la sociedad democrática y el Estado constitucional. La derrotabilidad se relaciona, así, jurídicamente con la Constitución (entendida como norma jurisprudencia y doctrina) a través de tres enfoques investigativos (dogmático, sociohistórico y axiológico). Cada enfoque muestra una relación problemática específica que es necesario establecer y resolver. Con ello, el objetivo de la presente fue Determinar la relación jurídica entre derrotabilidad de la norma y Constitución.

\section{Materiales y métodos}


El artículo se basó en una metodología básica, dado que se trató de la formulación de un conocimiento nuevo, basado en la sistematización de nociones jurídicas, mediante una orientación teórica deductiva. El tipo de estudio fue jurídico-comparativo. El método seguido fue el deductivo. También se aplicó el método analítico y de síntesis, desbrozando la derrotabilidad en tres dimensiones, con la finalidad de generar conocimiento novedoso desde tres enfoques jurídicos (dogmático, sociológico y axiológico).

Se presentó un triple diseño. $1^{\circ}$, enfoque dogmático jurídico, el cual abordó la derrotabilidad desde el concepto jurídico de validez, en esta virtud se trató de un estudio abstracto (sede teórica). $2^{\circ}$, enfoque socio jurídico. Se abordó la derrotabilidad y su vínculo con la Constitución Política del Perú mediante la relación de eficacia (experiencia jurídica). En este extremo se trató de observar cómo se cumplía en la realidad el principio de derrotabilidad. $3^{\circ}$, el aspecto axiológico-jurídico, que se enfocó en el principio de legitimidad para abordar la relación entre derrotabilidad de la norma y constitución.

La unidad de análisis se compuso de tres elementos jurídicos: validez, eficacia, legitimidad. Por ello, la muestra fue:

1. 20 trabajos académicos que conecten las variables con el concepto de validez.

2. 20 trabajos académicos que relacionen las variables con el concepto de eficacia.

3. 20 trabajos académicos que relacionen las variables con la legitimidad.

4. 10 jurisprudencias relacionadas con las variables.

5. 3 expertos en Derecho constitucional y teoría general del Derecho.

En estas se aplicó las siguientes técnicas de revisión documental y entrevista de preguntas abiertas para los expertos.

\section{Resultados y discusión}

Este estudio se propuso determinar la relación jurídica entre derrotabilidad de la norma y Constitución. Para ello, se entendió por relación jurídica una relación de validez, de eficacia y de legitimidad. Así, se tuvo un triple enfoque: dogmático jurídico, socio jurídico y axiológico jurídico. El primer problema, lógico jurídico, encontró un obstáculo inicial en su definición. Ramírez (2019) reduce el problema a simple incompatibilidad y una adecuada aplicación de las técnicas de interpretación. En tanto, Manrique (2019) sostiene que el razonamiento jurídico que exige la derrotabilidad jurídica en el Estado Constitucional tiene que obedecer a la moral legalizada reconocida constitucionalmente. Pulido (2018), en un estudio sobre la derrotabilidad de las normas sostiene que siendo la derrotabilidad una propiedad contingente de las reglas jurídicas, no es posible elaborar una caracterización general sobre cómo opera en cada una de las prácticas jurídicas. Esta limitación en la caracterización de la aplicabilidad de la derrotabilidad pasa por la inexistencia en la doctrina de una definición que considere dimensiones que sean de aplicación universal. En la misma dirección, Sacristán (2017) enfoca la derrotabilidad desde la 
noción de dignidad humana que implica tanto la superioridad de los seres humanos sobre otros seres vivos, como la potencialidad asociada a la humanidad. Nuevamente, el factor legitimidad se superpone al de validez y eficacia jurídica. De igual modo, se queda en que la mejor forma de entender qué es exceptuar una norma es con un concepto que permite esclarecer los actos mediante los cuales se reduce el ámbito de aplicación de las normas. Abiertamente reconoce la ausencia de una definición.

Pastor (2019), desde un enfoque socio jurídico de eficacia e impacto en la sociedad afirma que un alto nivel de errores judiciales efectuados por los operadores de justicia en el sistema jurídico peruano es causado, por la indebida aplicación normativa de los órganos que administran justicia. Este planteamiento se refiere, más que a la legitimidad o validez, al problema de eficacia jurídica en cuanto a reconocimiento de derechos fundamentales. Beltrán (2019), en cambio, se enfoca en aplicación de la derrotabilidad de las normas en materia procesal(es decir de impacto sociojurídico) y señala que es necesario que una vez que se haya realizado el respectivo análisis de las vicisitudes planteadas a través de la derrotabilidad y con el fin de evitar la jerarquía móvil se haga un pronunciamiento tendiente a la unificación jurisprudencial frente a las disposiciones problemáticas acerca de los casos de los procesos ejecutivos, la condena en costas, etc.

El único estudio desde una óptica lógico-jurídica es el de Magasich (2016), quien señala que la derrotabilidad es la decisión en que, encontrándose una situación cubierta por la regla, el decisor inaplica la regla. Esta se caracteriza porque las reglas dejan de ser tomadas como razones excluyentes de la deliberación. Sin embargo, no señala el procedimiento para su inaplicación. No obstante, no distingue entre derrotabilidad e inaplicación. Medeiros et al. (2020) recomiendan que se utilice la teoría de la derrotabilidad para superar el estándar normativo original, a fin de preservar la dignidad humana de la víctima y la eficacia de la jurisdicción penal. Entonces, no existe una definición dogmática jurídica de validez de este concepto, aunque admite que el factor de legitimidad (el principio de dignidad humana) es inderrotable, pues es el sustento del sistema democrático actual. También lo ve cual mecanismo de eficacia de la jurisdicción.

Condensando la información, se puede afirmar que la doctrina más actual expresa un serio problema de definición de la noción de derrotabilidad, que no existe un sistema integrado por específicas dimensiones que presente la derrotabilidad desde una óptica lógico-jurídica. Por el contrario, se presenta una derivación de validez desde la legitimidad. Significa que desde el principio de dignidad humana (inderrotable axiológicamente) se valida y se torna eficiente. Igualmente, esta falta de definición actúa como un ángulo peligroso ante la jurisprudencia. Así, se termina validando y legitimando instituciones que expresan ofensas contra el concepto (cadena perpetua, prohibición de beneficios penitenciarios, uso abusivo de la prisión preventiva, testigos con clave secreta, etc.).

En este orden, se propuso en primer término una definición de derrotabilidad partiendo de Hart (1961) quien estableció dos tipos de derrotabilidad. La primera implica coincidencia de las normas, relación interna y conclusiones con razonamiento lógico, la segunda de tipo sustantiva. Se aborda la derrotabilidad de la norma desde tres dimensiones teórico-explicativas. Primero, la teoría de la incompleta formulación de los conceptos jurídicos; segundo, la teoría de los deberes prima facie; y, tercero, la 
distinción jurídica entre reglas y principios. Estas tres teorizaciones permitirán la compresión cabal del concepto jurídico de derrotabilidad y su relación con la Constitución.

Sobre la teoría de la incompleta formulación de los conceptos jurídicos, Ross (1994) concibe que es imposible establecer si determinados conceptos jurídicos son aplicables mediante un esquema cerrado de presupuestos teóricos. En este extremo, la teoría textura abierta del Derecho (Arias, 2018) implica que en el mundo de las reglas jurídicas existe un confín inherente a la esencia del lenguaje, específicamente ligado a la sugerencia que el lenguaje general proporciona. Las situaciones sometidas a la norma componen una zona de claridad. Los escenarios no sometidos a la norma componen una zona de oscuridad; finalmente, otros entornos subsistirían en una zona de penumbra.

La teoría de los deberes morales prima facie, también formulada por Ross (1994), postuló un ligado de siete deberes: fidelidad, reparación, gratitud, beneficencia, mejora y no maleficencia. En caso de generar conflicto práctico, se soluciona con la supremacía a un deber sobre otro. Es un enfoque práctico de las obligaciones morales. Primero, ninguna tiene carácter absoluto; pues atendiendo las características de un problema, un deber puede ser derrotado por otro que, en la situación concreta, está destinado a prevalecer. Por último, se desarrolla la teoría de las Reglas y principios de Alexy (2000) quien ve a las reglas como normas que pueden ser cumplidas o no. En cambio, los principios son normas con niveles de cumplimiento en diferente grado. Este concluye que las reglas son mandatos definitivos, opuestos a los principios, entendidos como mandatos de optimización. Las reglas son cumplidas absolutamente; los principios son progresivos.

En este orden, se propuso que la derrotabilidad admite excepciones. Toda regla tiene excepciones ya que sus condiciones internas le dan la capacidad de admitir estas; pero es esta misma capacidad la que la vuelve derrotable. Alexy soluciona la contradicción dándole a los principios el carácter de mandatos definitivos (que también son reglas) e introduce una distinción: mandatos para optimizar y mandatos a optimizar. Así, plantea que hay mandatos para optimizar reglas y de mandatos a optimizar (principios). Ambos (reglas y principios) configuran el mandato de optimización. (Bäcker 2014).

La derrotabilidad es un concepto con tres dimensiones lógico-jurídicas indesligables. Cualquier concepto jurídico es derrotable lógicamente debido a su contenido intrínseco siempre inacabado. Todo concepto está sujeto a un constante proceso de reformulación con el propósito de completarse como tal. Por otro lado, los deberes no ostentan en su diversidad un sistema jerárquico de deberes que en cada situación determine cuál predomina sobre los demás. Los deberes priman facie exhiben el mismo grado y son derrotables en función de la prevalencia que un deber concreto puede presentar respecto a otro bajo determinadas circunstancias. Del mismo modo, la distinción entre reglas y principios supone también la derrotabilidad de las reglas debido a que las normas existen para ser cumplidas (o no). Las reglas son cumplidas absolutamente; los principios se dan progresivamente. La teoría de la incompleta formulación de los conceptos jurídicos es esencialmente de carácter dogmático. La teoría de los deberes morales prima facie es axiológica y la distinción entre reglas y principios es dogmático axiológico.

- Propuesta de solución de problema - postura personal con fundamento teórico 
El problema de la presente recayó en determinar hasta qué extremo el rasgo distintivo de la derrotabilidad, vivo dentro de las normas jurídicas, afecta en el bordado de la interpretación de las normas constitucionales en un Estado constitucional como el peruano. Este aspecto es de relevancia debido a que los Estados constitucionales actuales presentan las condiciones adecuadas para que mediante postulados axiológicos se aplique e interprete el Derecho en base de la fuerza jurídica que les otorga la Carta Política.

Todo sistema jurídico vigente tiene como requisito ineludible la adherencia a principios y normas desde el mismo sistema (autoridades y funcionarios). El punto es que estos postulados actúen como justificación última, pues un sistema jurídico contemporáneo de carácter constitucional no puede existir sin la exigencia de reconocimiento moral. De este modo, la derrotabilidad se aborda desde un punto de vista teórico lógico dogmático, específicamente desde la noción de validez; pero también se presenta desde la práctica sociojurídica mediante la emisión de sentencias de índole constitucional, en este punto es clave la noción de eficacia. Finalmente, desde una óptica filosófica, se trata de intervenir en el problema desde los postulados generales del Derecho, específicamente, los del Estado constitucional. Se trata del establecimiento de la democracia deliberativa como paradigma político ideal jurídico-político de Estado. En este punto se habla de legitimidad. Se determinó que hay relación jurídica entre derrotabilidad de la norma y Constitución. No obstante, esta relación se ha logrado establecer mediante tres enfoques.

Un primer enfoque es el dogmático. En este extremo se observa que no existe una definición de síntesis respecto de la derrotabilidad de las normas. En tal sentido, se ha elaborado una definición que abarca tres vertientes: la teoría sobre la incompleta formulación de los conceptos jurídicos( con sus nociones de textura abierta del Derecho; segundo, las zonas de claridad, penumbra u oscuridad jurídica y; tercero, la crisis de comunicación que genera el derecho), la teoría de los deberes morales prima facie( con sus nociones sobre deber en sí, tipos de deberes, deberes como postulados de normas y la interacción entre ellos) y la distinción entre reglas y principios(entendidos los últimos como de cumplimiento progresivo de optimación).

Un segundo enfoque es de carácter socio jurídico, pues la derrotabilidad como figura jurídica se presenta en la jurisprudencia constitucional. En efecto, del análisis jurisprudencial se expresa el problema de la eficacia de la derrotabilidad. Se trata de un concepto que sirve para resolver problemas vivos en los cuales muchas veces hay un conjunto de reglas y principios contrapuestos. El juez constitucional por lo general resuelve este tipo de conflicto de deberes mediante un conjunto de mecanismos. Por otro lado, es posible observar operadores de justicia que no fallan acorde a los postulados de un Estado de Derecho. Las causas de este fenómeno se encuentran en la precaria formación ideológica democrática y constitucional tanto de la sociedad civil como de la institucionalidad. En efecto, la falta de reacción institucional frente a este fenómeno trae como consecuencia que el Derecho en la práctica histórica social no sea vinculante para la jurisdicción constitucional, o que los veredictos de esta obedezcan a un criterio arbitrario y anárquico o que tal insujeción sea avalada por el poder estatal y la sociedad.

Desde una visión axiológica, se enfrenta la derrotabilidad con la dignidad humana y Estado constitucional de Derecho. Los modelos constitucionales más modernos han puesto al ser humano y su dignidad como fines del Estado y la sociedad. Esto implica que hay un determinado ligado de derechos 
que desde un punto de vista valorativo no están supeditados a derrota y ni a consecuente regresión hacia estándares premodernos de derechos. No obstante, se presentan en el Derecho figuras jurídicas que contravienen derechos fundamentales de carácter inderrotable. Por ejemplo, cadena perpetua, prohibición de beneficios penitenciarios o testigos con clave secreta. El concepto axiológico de derrotabilidad en ocasiones suele estar de cabeza dado que hay reglas (como la seguridad ciudadana, bajo un discurso de emergencia penal) que derrotan principios que gozan de reconocimiento por parte de toda la comunidad internacional y que se relacionan con un tinglado de derechos que nacen desde el principio de dignidad humana cuya esencia debe ser protegida como fin supremo del Estado y la sociedad.

\section{- Consecuencias de la implementación de la propuesta}

\section{Sobre la relación de derrota habilidad con la teoría de la incompleta formulación de los conceptos jurídicos de Hart, 1961}

Conforme la propuesta de Hart, la derrotabilidad consiste en una técnica para la resolución de problemas entre normas. Se trata de una técnica jurídica, mediante la cual los jueces ejercen su "poder de creación intersticial de derecho" sin que ello signifique crear radicalmente nuevas normas para resolver un caso ante una falta de coherencia o congruencia en las propias normas jurídicas.

El problema principal desde la óptica presente fue la falta de una definición que condense a los diferentes matices conceptuales establecidos en la dogmática jurídica general sobre derrotabilidad. Ello acarrea confusión, pues la derrotabilidad se confunde con validez e inaplicación. Es menester plantear una definición síntesis de derrotabilidad considerando la teoría de Hart sobre la incompleta formulación de los conceptos. No es jurídicamente posible establecer previamente un supuesto jurídico que aborde hipótesis no predecibles en base a un examen preliminar abstracto dado que los conceptos jurídicos responden a casos típicos normales a los que se les agrega de modo posterior algunas excepciones. Por tanto, este concepto parte de la idea de que resulta imposible determinar todos los aspectos de un concepto jurídico en base a un esquema cerrado de supuestos teóricos.

\section{Sobre la noción de derrotabilidad y su vínculo con la teoría de los deberes prima facie de Ross (1994).}

Dado que Ross fundamenta su noción a partir de una postura crítica al utilitarismo, los deberes llevan a dotar de un contenido fuerte de moralidad, por lo que no es posible elaborar una jerarquización entre ellos. Así, toda colisión entre ellos, observable a partir de la casuística, configuran una situación de precedencia. Sin embargo, dichas situaciones no dejan de ser específicas y los presupuestos derivados de la derrotabilidad operan en función de las características específicas del caso concreto. Reconozco que mi respuesta es vaga, dado que la pregunta se abre a otros ámbitos de la discusión. No debe olvidarse que la teoría del derecho de Ross tiene que ver con el realismo jurídico.

Es absurdo establecer una jerarquía que los distinga dado que todo deber moral debe tener la misma jerarquía y las mismas condiciones de obligatoriedad con respecto a su cumplimiento; pero el problema de fondo es que esto será válido con la condición de que no se presente un conflicto en la 
práctica entre deberes porque de darse el caso debe establecerse la supremacía necesariamente de un deber sobre otro. En tal sentido, existe un enfoque pragmático respecto de las obligaciones morales, siguiendo la teoría de Ross, pues ninguna obligación moral tiene carácter absoluto y un deber puede ser desarrollado y derrotado por otro en una situación específica.

Desde otro ángulo, la teoría de la incompleta formulación de los conceptos jurídicos tiene un enfoque básicamente dogmático; en cambio, la teoría de los deberes morales prima facie es, esencialmente, axiológica, pues se basa en postulados y valores; a diferencia de la distinción entre reglas y principios que es, a su vez, tanto dogmática como axiológica.

\section{Sobre la noción de derrotabilidad y su relación con la distinción teórico-dogmática entre reglas y principios (Bäcker, 2014)}

Bäcker parte de la distinción alexyana entre reglas y principios, pero opta por identificar un criterio que reconozca con más detalle tal distinción. Ese criterio no sería otro que la derrotabilidad, el cual desplaza al contenido deóntico gradual de la optimización con el que Alexy identificó el cumplimiento de los principios. En este sentido, el autor entiende la derrotabilidad como "la capacidad de admitir excepciones", mediante el cual se contempla un conjunto de supuestos abierto para las reglas, y cerrado para los principios

Desde otro punto de vista la contradicción entre reglas y principios no nace de la noción de derrotabilidad; sino, por el contrario, de la noción de cumplimiento; en efecto, las reglas son normas que simple y llanamente pueden ser cumplidas (o no); pero los principios se distinguen porque son normas con grado de cumplimiento en un alto nivel, de tal modo que las reglas se convierten en mandatos definitivos, en contradicción con los principios que constituyen mandatos de optimización; esto significa que las reglas deben cumplirse de modo absoluto y los principios deben cumplirse de modo progresivo.

En otra óptica, la diferencia entre reglas y principios deriva en la derrotabilidad de las reglas, toda vez que estas existen para su acatamiento o no acatamiento; en este orden, la doctrina jurídica constitucional es pacífica respecto a que las reglas deben cumplirse de modo absoluto; en cambio, los principios deben cumplirse de manera progresiva.

\section{Sobre la noción de derrotabilidad y su relación con la eficacia (Bobbio, 1994)}

La noción de eficacia en Bobbio responde a la concepción y distinción que el citado jurista elabora sobre norma jurídica en relación con el ejercicio del poder. Las normas eficaces resultan indispensables para asegurar el funcionamiento del sistema normativo, es decir, el cumplimiento y obediencia de las disposiciones normativas en el Estado de Derecho. La eficacia es una seña de identidad de las normas jurídicas

Para Bobbio, justicia y eficacia deben ser diferenciadas; por ejemplo, las regulaciones del derecho natural que sostienen doctrinas metafísicas, como principios universalmente válidos, en todo tiempo y lugar, promulgado supuestamente por una deidad que tiene una voluntad que trasciende, y que es y 
descubrible mediante la razón humana mediante la racionalidad. Estos conceptos no son practicados siempre y en todo lugar y según la sociedad establecen diferenciaciones No obstante se entienden como ideales.

Para Bobbio las nociones de justicia, validez y eficacia tienen por separado un orden propio que debe ser distinguido; y que no necesariamente coinciden, pues toda norma jurídica, incluso un sistema jurídico, puede existir en una comunidad determinada. No obstante, el contenido puede colisionar con la moral de dicha comunidad. Así, la teoría general del derecho debe tener un triple orden en la valoración de la norma, esto es, si la norma jurídica es justa, si la norma jurídica es válida; y, si la norma jurídica es eficaz.

\section{Sobre la noción de derrotabilidad y su relación con la de eficacia (Bobbio; 1994) en cuanto al principio de eficacia-existencia}

Un concepto central en el planteamiento de Bobbio reside en la identificación de las fuentes del derecho y la producción de normas. Dada la complejidad de los ordenamientos jurídicos, la necesidad de regular la relación y orden entre las fuentes es relevante para mantener la unidad de un determinado ordenamiento jurídico. De ahí que destaca el principio de jerarquía que ordena los conjuntos de normas, con la Constitución en la cima, aspecto en el que Bobbio coincide con Kelsen. En este sentido, la derrotabilidad se manifestará con más fuerza en los conjuntos de normas más cercanos al vértice, y dada las relaciones entre derecho y poder, puede producirse una derrotabilidad radical de normas: la discrecionalidad judicial opera con criterios externos al derecho.

En el plano jurídico, el valor solo se circunscribe a lo que determina una norma jurídica; esto es, lo que la norma obliga prohíbe consciente respecto de determinada acción. En este sentido, el valor es entendido cómo sentido objetivo en relación con un comportamiento respecto de la norma objetiva que goza de validez y no en relación con el deseo o voluntad de una persona. Bobbio sostiene que una norma puede ser válida y sin embargo puede ser injusta irreprochable desde el punto de vista

Desde otro ángulo, la validez de la norma no aborda el hecho de que sea justa o injusta; pues hay normas jurídicas que respecto a su justicia no deberían ser efectivamente aplicables; pero eso no significa que su ineficacia derive de su invalidez. Para Bobbio la validez y la eficacia son nociones conceptuales separadas; del mismo modo que también son separadas la eficacia como la justicia, dado que la noción de lo eficaz no es derecho y la noción de derecho no siempre resulta eficaz.

Significa que la noción de Justicia validez y eficacia poseen cada cual un orden propio que puede ser estudiado y evaluado por separado y diferenciado de otros implica que no coinciden. Por eso, se dice que es obedecida al cumplir los requisitos de validez justicia y eficacia ya que el problema de la validez de una norma se resuelve con un juicio de existencia o De hecho de la norma y se establece con 3 criterios: primero, determinar si la autoridad que promulgó tenía poder legítimo; segundo, comprobar si la norma no fue denegada y, tercero, comprobar que no sea incompatible con otras normas del sistema. 
6. Sobre la noción de derrotabilidad y su relación con la de eficacia (Bobbio; 1994) en cuanto al principio de eficacia-efectividad

La noción de la eficacia alude a las condiciones fácticas ligadas al poder que permite que el contenido deóntico de las normas sea observado por los integrantes de un sistema jurídico. En este sentido, la validez está ligada al poder como presupuesto fáctico en el que se configuran las relaciones de deber y obediencia. Se reafirma el sistema de normas, con la Constitución como norma fundamental y regla de reconocimiento jurídico-política.

Hay normas jurídicas que no son efectivamente aplicables; pero esto no significa que, de su eficacia pueda derivarse su invalidez. En conclusión, validez y eficacia son nociones conceptuales separadas; así también, la eficacia y la justicia, puesto que todo lo eficaz no es necesariamente derecho; y, todo lo que es derecho no siempre resulta eficaz.

Finalmente, que una norma exista en cuanto a norma jurídica no significa que también sea constantemente. En este orden, hay normas que se cumplen universalmente de manera espontánea y son mucho más eficaces que otras que se cumplen por lo general únicamente cuando van acompañadas de coacción.

7. Sobre la noción de derrotabilidad y su relación con la de legitimidad en cuanto al indicador de Principios del derecho

Es un concepto central para resolver conflictos entre principios. El criterio de legitimidad en el Estado constitucional de Derecho viene dado por los derechos fundamentales, fundados en los principios kantianos de dignidad, inviolabilidad y autonomía. Dado que no se puede establecer un orden jerárquico entre ellos y resolver prima facie los casos concretos, un supuesto de indeterminación del derecho que exija operar a nivel de principios requiere que la actividad interpretativa de los jueces de cuenta tanto de los defectos lógicos como de las indeterminaciones lingüística. Por el contrario, la derrotabilidad, como característica de las normas jurídicas cuando adolecen de coherencia normativa o congruencia, deviene la impronta de Raz respecto a la definición de norma jurídica como razón protegida para la acción y decisión judicial.

Deben considerarse: $1^{\circ}$, que la norma puede ser justa sin ser válida; $2^{\circ}$, que una norma puede ser válida sin ser justa; $3^{\circ}$, que una norma puede ser válida sin ser eficaz; $4^{\circ}$, que una norma puede ser eficaz sin ser válida; $5^{\circ}$, que una norma jurídica puede ser justa sin ser eficaz; $\mathrm{y}, 6^{\circ}$, puede ser eficaz sin ser justa. Más allá de la norma positiva los principios generales del derecho son principios superiores de justicia, cuya raíz se encuentra fuera del derecho positivo. Como consecuencia, se les brinda una encarnación que es reflejo de una circunstancia histórica concreta. En tal sentido, son ideas fundamentales sobre la organización jurídica de una comunidad, producto de la subjetividad social de su grado de conciencia a nivel fundamentador interpretativo y supletorio de un ordenamiento total.

\section{Sobre la noción de derrotabilidad y su relación con la de legitimidad en cuanto al indicador} instrumentos internacionales 
Respecto a los instrumentos internacionales, podemos remitirnos a la sistematización de fuentes que plantea Bobbio. Resulta importante destacar que la complejidad que se desprende de la interacción entre los diferentes sistemas de fuentes no constituye un factor que debilite cuando operamos en el marco del ideal racional de completitud y coherencia de los sistemas normativos. Pero operar a nivel de la coherencia o congruencia entre normas ya es más complejo: derrotabilidad de prescripciones contenidas en la formulación sintáctica y semánticas de las reglas y derrotabilidad en el nivel de las razones subyacentes a las reglas, principios implícitos y explícitos.

Bobbio considera Declaración Universal de los Derechos Humanos establecida por la Asamblea General de las Naciones Unidas 1948 es apenas el inicio de un largo proceso de incorporación de Derechos Humanos. No obstante, no inválida el interés por la fundamentación filosófica dado que dicha fundamentación contribuye a profundizar su conocimiento. Bobbio plantea la postura del intersubjetivismo axiológico, teoría que le permite determinar la racionalidad práctica para tener consenso respecto a los derechos humanos y evitar extremos. Los derechos humanos reconocidos en instrumentos internacionales constituyen categorías históricas; esto es, derechos históricos que surgen de modo gradual en medio de las pugnas que tiene la humanidad en función de su emancipación y la búsqueda de la transformación de sus condiciones de vida.

\section{Sobre la noción de derrotabilidad y su relación con la de legitimidad en cuanto al indicador principio de dignidad humana}

El principio de dignidad humana permite observar que la relación entre la derrotabilidad y legitimidad es de medio a fin. En tanto que las normas jurídica pueden tener problemas de coherencia o concordancia práctica, cabe advertir el mecanismo de derrotabilidad radical, es decir, dado que el principio de legitimidad depende de comprensiones de filosofía ético política, frente a problemas de complejidad casuística y de indeterminación se acuda discrecionalmente a soluciones extrajurídicas o a criterios no compartidos por la comunidad jurídica; en este sentido, es importante explorar la diferencia entre convencionalidad superficial y profunda para dar salidas de coherencia en la protección y garantía de derechos sin descuidar el principio del proceso democrático. La legitimidad no sólo deviene del principio de dignidad humana sino también del proceso democrático.

Pero ¿acaso no ha sido superada la tesis de Bobbio propuesta en la década de los 70 respecto de lo verdaderamente significativo para los derechos humanos?, dado que su problema no radica tanto en su fundamentación; sino principalmente en su real protección; de tal modo que la comunidad internacional y los gobiernos estatales estén del todo comprometidos para generar mecanismos por los cuales se garantice el real vigor de los derechos humanos No obstante, todo lo señalado, la expresión dignidad de la persona humana puede traer paradojas; de tal manera que, la civilización actual, vista en el contexto de pandemia generada por un virus creado en un laboratorio, representa una amenaza contra la dignidad humana nunca vista en todo el proceso histórico. Si bien algunas civilizaciones ignoraron el principio de dignidad humana, la sociedad actual ha conseguido extender la idea junto al respeto y garantías mínimas e iguales para todos, presenta una poderosa tendencia a la completa eliminación de la idea misma de dignidad. 


\section{Sobre el nivel de avance en jurisprudencia constitucional respecto de la noción de} derrotabilidad en el Perú

En la jurisprudencia del Tribunal Constitucional del Perú es posible apreciar algunas manifestaciones de la derrotabilidad, en especial en algunas líneas jurisprudenciales. En el caso particular del derecho de acceso a la información pública se aprecia cómo a partir de las reglas de derrotabilidad, el colegiado no restringió el principio de publicidad dadas las antinomias que este configura con la reserva. Por el contrario, la introducción de excepciones a partir de la derrotabilidad permitió que el Tribunal Constitucional elaborara una jurisprudencia coherente con los principios de dignidad humana y del Estado democrático de derecho, tal como se aprecia en la sentencia recaída en el Expediente No 00005-2013PI/TC. La STC 06712-2005-HC. Caso Magaly Jesús Medina Vela y Ney Guerrero Orellana. (Huayaconza, 2018). En este caso se ha señalado que la institución del domicilio, constitucionalmente hablando, es amplia; de tal modo que una habitación de hotel donde un particular cultiva su profesión se constituye domicilio u oficina y debe ser entendida como tal. Se trata de la inviolabilidad de domicilio. El criterio cerrado de domicilio es derrotado mediante la expansión de dicha noción hasta "actividades realizadas por una persona en la habitación de un hotel".

\section{Sobre el nivel de avance en la jurisprudencia constitucional respecto de la noción de derrotabilidad en la jurisprudencia internacional}

El juez constitucional tiene un margen de interpretación que permitiría identificar las excepciones a partir de la resolución de casos concretos. Sin embargo, la línea distintiva entre actividad interpretativa y creación discrecional sigue siendo difusa. Al respecto, coincido con el tratamiento de Ródenas (2012) para distinguir ambos espacios y, para responder adecuadamente esta pregunta, debería precisarse a qué derecho fundamental o a qué línea jurisprudencial se refiere a la hora de evaluar el nivel de avance de la derrotabilidad como técnica en la jurisprudencia internacional. La derrotabilidad se articula a la teoría de la norma jurídica y en general a la filosofía del Derecho respecto de los sistemas normativos en el marco de un Estado democrático y social de Derecho.

Se destaca el Auto 785/07 del 18 de octubre de 2007 del juzgado de Primera Instancia de Sevilla (Ruiz, 2012). Se trata de una niña que solicitaba con apremio un trasplante de hígado. Debido a las peculiaridades de la operación (la donante era la propia madre). Pero era una madre menor de edad. Por tanto, se le impidió ejercer un hecho de tal naturaleza.

Debe considerarse el Fallo de Tribunal Constitucional Federal alemán 1996. falló en 1996 la validez constitucional de un conjunto de sentencias penales que castigaban por homicidio causado por sucesos acontecidos en 1984. Debe añadirse que para el Derecho aplicable en ese preciso espacio temporal tales hechos no representaban una conducta típica y antijurídica. Esta decisión contravino abiertamente el $103^{\circ} 2$ de la Ley Fundamental de Bonn prohibiendo la figura de irretroactividad maligna de la ley penal.

12. Sobre el nivel de avance en jurisprudencia constitucional respecto de la noción de derrotabilidad en jurisprudencia supranacional 
De manera similar a la respuesta anterior, se debe precisar un ámbito específico que permita realizar una valoración más precisa en torno al nivel de avance de la aplicación de las reglas de la derrotabilidad. En el caso de la jurisprudencia constitucional peruana, ya existe una apertura al diálogo con la jurisprudencia supranacional, tanto en las decisiones mayoritarias de los magistrados como en sus votos singulares; sin embargo, hay que profundizar en la observación de líneas jurisprudenciales específicas para evaluar la derrotabilidad con mejores resultados y aportes para la investigación jurídica, en el marco del debate sobre teoría y taxonomía de la norma jurídica.

Es el caso del Tribunal Constitucional español cuando en 2003 so pretexto de defensa del derecho a la libertad de información favoreció la propagación de un conjunto de pormenores personales derivados de una causa judicial que todavía no arribaba a la fase de juicio oral. No obstante, el artículo $301^{\circ}$ de la Ley de Enjuiciamiento Criminal española, exigía el secreto de las diligencias sumarias hasta la etapa del juicio oral.

La Corte Interamericana de Derechos Humanos (2018) ha señalado que todo Estado parte de la Convención Americana (órganos jurisdiccionales, jueces y demás operadores de justicia en todos los grados) se encuentran supeditados a la Convención Americana sobre Derechos Humanos. Esta disposición obliga a que los preceptos de la Convención no sean reducidos a causa de la aplicación de normas contrarias a su esencia. Añade que todo fallo judicial no debe transformar en utópico el acatamiento total o parcial de obligaciones internacionales. Por tanto, se entiende que toda autoridad tiene la obligación de realizar control de convencionalidad ex officio sobre las normas internas y la Convención Americana. Concluye en la significancia que tiene no solo tomar en cuenta el tratado sino también la interpretación que hace el intérprete último de la Convención Americana.

\section{- Beneficios que aporta la propuesta}

La derrotabilidad está en íntima relación con la noción de la teoría de la incompleta formulación de los conceptos jurídicos. Es visto como un poder de creación intersticial de derecho. Por otro lado, se parte de la idea de que no existe una teoría que condense los diferentes puntos de vista jurídico sobre la derrotabilidad; lo cual crea confusión, dado que todo concepto jurídico, en rigor, desde el punto de vista de Hart, siempre será incompleto. Esto no significa que sufra de problemas de validez o inaplicación; al contrario, los expertos coinciden en que en los conceptos jurídicos, toda vez que responden a casos típicos y normales, resulta inconcebible abordar sus aspectos desde un esquema cerrado que no se reformule constantemente, autocompletándose; de tal modo que aborde todos los casos para los que fue diseñada la norma.

Significa que la derrotabilidad consciente excepciones; esto es completamente entendible, pues existe la regla y siempre está supeditada a excepciones, debido a sus ligados interiores que le permiten tener la facultad para aceptar dichas excepciones. Sin embargo, esa misma capacidad para admitir y aceptar excepciones es, precisamente, la que la convierte en derrotable. De esta manera, la solución solamente puede resolverse solo si a los principios se les otorga la esencia de mandatos definitivos, especie de reglas; de tal modo que se introduzca una distinción mandatos para optimizar y mandatos a optimizar. 
El problema de la diferencia entre reglas y principios se entiende mejor desde la noción de derrotabilidad. Implica la firmeza en los principios; pero flexibilidad en la aplicación de las reglas; de tal manera que las reglas cuentan con un sistema abierto y los principios con un sistema esencialmente dogmático (entendido como postulado inamovible que debe ser conseguido socialmente de manera progresiva dado que su cumplimiento ideal a cabalidad siempre será un propósito más que una meta).

La eficacia resulta del impacto positivo de la norma, entendiendo el vocablo positivo como favorable al orden; no obstante, esta eficacia no necesariamente se condice con los principios del derecho o la justicia. Significa que la noción de justicia, validez y eficacia poseen cada cual un orden propio que puede ser estudiado y evaluado por separado y diferenciado de los demás. Implica que no coinciden, por eso se dice que una norma es obedecida cuando cumple los requisitos de validez, justicia y eficacia.

La eficacia se refiere al seguimiento o acatamiento de la norma. Una norma es eficaz si la población la cumple con independencia de si la percibe como justa o válida e inefícaz; o si es ampliamente desobedecida. Es el caso de la prohibición de aparcar en una zona prohibida que suele ser percibida por la comunidad como algo justo, de tal manera que se trata de una prohibición válida; pero la eficacia se refiere al cumplimiento de los fines que la sociedad considera como buenos; una norma es injusta si la población considera mayoritariamente que no se atiene a los objetivos colectivos de tal sociedad; $\mathrm{y}$, considera que es injusta si ocurre lo contrario con independencia de si es válida o no.

La función de los principios del derecho no se reduce únicamente al problema de las lagunas existentes en una legislación sino a toda una experiencia jurídica que constituye el conjunto de pilares y muros maestros de la estructura jurídica. Esto implica que, con esos principios, se interpreta y aplica los modelos jurídicos sobre una relación social cuya juridicidad tiene que ser determinada judicialmente, aunque haya dificultades de ajuste.

Se requiere una nueva lectura diferenciada de la fundamentación tradicional que dan a los principios una naturaleza absoluta y eterna; es necesario considerar a los derechos humanos en cuanto a sistema de valores consensuados; de tal modo que el valor más fundado sería el más compartido, el más aceptado; así, los derechos humanos no son tablas esculpidas de una vez para siempre; sino representan una etapa de la conciencia histórica humana; es una especie de síntesis del pasado y una determinación de propósitos hacia el porvenir dentro de un proceso histórico largo de reconocimiento de libertades.

La posición sobre la dignidad humana pasa por el reconocimiento del dolor del otro, del sufrimiento del que no tiene poder; es un dolor constitutivo de la objetividad humana; la historia en tiempos recientes ha demostrado sus desastrosas consecuencias: la Alemania nazi, las guerras en la antigua Yugoslavia, miles de millares de muertos en África, violaciones innumerables de Derechos Humanos en América Latina, millones de muertes por la guerra y el intervencionismo, y una pandemia, demuestran que la violación de la dignidad de las personas no es excepcional, sino, un patrón normalizado.

Existe jurisprudencia del Tribunal constitucional, por ejemplo, la Sentencia del Tribunal Constitucional, expediente $\mathrm{N}^{\mathrm{o}} 2730$-2006-PA. El recurrente interpone demanda de amparo contra el 
Jurado Nacional de Elecciones (JNE), con la finalidad de que se declare la nulidad de una Resolución emitida en un procedimiento que declaró su vacancia en el cargo de Alcalde del Concejo Provincial de Chiclayo, pues considera que vulnera el derecho fundamental al debido procedimiento administrativo y a la debida motivación de las resoluciones y contraviene la proscripción de avocamiento a causas pendientes ante el órgano jurisdiccional. La jurisprudencia acerca de la derrotabilidad de la norma es una constante en la práctica judicial internacional.

Sobre el Artículo 26 de la Convención Americana sobre Derechos Humanos. Se tiene que los Estados Partes se comprometen a adoptar providencias, tanto a nivel interno como mediante la cooperación internacional, especialmente económica y técnica, para lograr progresivamente la plena efectividad de los derechos que se derivan de las normas económicas, sociales y sobre educación, ciencia y cultura, contenidas en la Carta de la Organización de los Estados Americanos, reformada por el Protocolo de Buenos Aires, en la medida de los recursos disponibles, por vía legislativa u otros medios apropiados.

\section{Conclusiones}

Como conclusión general se ha determinado que existe relación jurídica entre derrotabilidad de la norma y Constitución. En efecto, desde los enfoques dogmático jurídico, socio jurídico y axiológico se ha podido dimensionar la existencia de esta relación entre las variables de estudio.

Se determinó la relación dogmático-jurídica entre derrotabilidad de la norma y la Constitución. En efecto, teoría de la Incompleta formulación de los conceptos jurídicos, la teoría de los deberes prima facie de Ross y la distinción entre reglas y principios condensan teóricamente la noción de derrotabilidad. Estos conceptos, respectivamente, significan, primero, que todo concepto teórico-jurídico siempre será incompleto (no por problemas de validez o inaplicación) porque los conceptos jurídicos se autocompletan y reconfiguran para abarcar todos los casos para los que fueron diseñados en forma de norma. Segundo, la noción de derrotabilidad consiente excepciones; sin embargo, tal capacidad es, precisamente, quien le da la condición de derrotable. La solución es que a los principios se les reconozca la esencia de mandatos definitivos, de tal manera que se introduzca una distinción entre mandatos para optimizar y mandatos a optimizar. Y, tercero, las reglas cuentan con un sistema abierto y los principios con un sistema esencialmente dogmático, entendido como postulado inamovible que debe ser conseguido socialmente de manera progresiva.

Asimismo, se determinó la relación sociojurídica entre derrotabilidad de la norma y la Constitución. En efecto, desde el análisis del fallo del Tribunal constitucional federal alemán de 1996, el fallo del Tribunal constitucional español de 2003 y los del Tribunal Constitucional peruano, se tiene que la eficacia resulta del impacto positivo de la norma entendiendo el vocablo positivo como favorable hacia el orden No obstante, esta eficacia no necesariamente se contradice con los principios del derecho; sin embargo, todas estas nociones poseen cada cual un orden propio que puede ser estudiado y evaluado por separado y de modo diferenciado. La eficacia es el acatamiento de una norma. 
Finalmente, se determinó la relación axiológica entre derrotabilidad de la norma y la Constitución. En efecto, desde los Principios del Derecho, Instrumentos internacionales y el principio Dignidad del ser humano, se tiene que la función de los principios del derecho no se reduce únicamente al problema cubrir las lagunas existentes en una legislación; sino a toda una experiencia jurídica que constituye el conjunto de pilares y muros maestros de la estructura jurídica civilizada. Por esta razón, es necesario considerar a los derechos humanos en cuanto a sistema de valores consensuados; de tal modo que el valor más fundado sea el más aceptado y constituya, per se, prueba de objetividad; Además, los Derechos Humanos representan una etapa de la conciencia histórica humana; son síntesis de propósitos hacia el porvenir dentro del reconocimiento de libertades. La posición sobre la dignidad humana pasa por el reconocimiento del dolor del otro, del sufrimiento del que no tiene poder; es un dolor constitutivo de la objetividad humana

\section{Referencias bibliográficas}

Alegre, J. (2017). La epistemología naturalizada de los principios jurídicos. Ius Inkarri, (6), 157172. http://168.121.49.88/index.php/Inkarri/article/view/1234

Alexy, R. (2000). Derecho injusto, retroactividad y principio de legalidad penal: La doctrina del Tribunal Constitucional Federal alemán sobre los homicidios cometidos por los centinelas del muro de Berlin.

Arango, E. \& Herazo, K. (2020). Neoconstitucionalismo, positivismo y validez. Revista de Derecho, 33(1), 31-52.

Arias, E. (2018). Textura abierta del Derecho Internacional de Inversiones, análisis del estándar de trato justo y equitativo (Bachillerato, Pontificia Universidad Católica del Ecuador). http://repositorio.pucesa.edu.ec/handle/123456789/2244

Bäcker, C. (2014). Reglas, principios y derrotabilidad.

Beltrán, D. (2019). Aplicación de la derrotabilidad de las normas en materia procesal. Análisis de las vicisitudes en las leyes 1437 de 2011 y 1564 de 2012. (Maestría, Universidad Libre el Socorro Santander, Bucaramanga.

Bobbio (1994). Teoría General del Derecho. Temis, Bogotá, pág. 20).

https://editorialtemis.com/Temis/Contenidos/13-000-0069.pdf

Caballero, P. (2017). Sobre la teoría de los conceptos jurídicos de Alf Ross. Explicitando sus presupuestos verificacionistas e inferencialistas. Isonomía, (47), 81-108.

Cristiano, J. (2017). Contribución al desarrollo de una teoría abstracta de la estructura social. Miríada: Investigación en Ciencias Sociales, 9(13), 71-91. 
Estay, J. (2019). Los conceptos jurídicos indeterminados en el lenguaje constitucional. Revista de Derecho politico, 1(105), 161-196.

Etcheverry, J. (2020). Una aproximación a los principios jurídicos desde su función de fundamentación. civilistica. com: revista eletrônica de direito civil, 9(1), 1-31. https://civilistica.emnuvens.com.br/redc/article/view/514

Fernández, J. (2019). Principialismo, garantismo, reglas y derrotabilidad en el control de constitucionalidad de las leyes penales. Nuevo Foro Penal, 85, 52.

García, A. (2003). La incidencia de la derrotabilidad de los principios iusfundamentales sobre el concepto de Derecho. Diritto \& Question Publiche, (3), 197-227.

Hart, H. (1961). El concepto de derecho (pp. 149-150). Buenos Aires: Abeledo-Perrot.

Huayaconza, S. (2018). El derecho a la imagen propia de una persona natural frente a los límites para su difusión en el Perú. http://repositorio.ucv.edu.pe/handle/20.500.12692/27415

Magasich, Á. (2016). La derrotabilidad, fraude de ley y cláusula general antielusiva. Análisis desde el Derecho tributario español y chileno (Programa de doctorado) Universitat de Barcelona, Barcelona. http://diposit.ub.edu/dspace/handle/2445/112462

Manrique, Y. (2019). Derrotabilidad jurídica en la inscripción de la candidatura presidencial de Julio Armando Guzmán Cáceres en el proceso electoral 2016. (titulación) Universidad Santiago Antúnez de Mayolo, Ancash. Metodología. http://repositorio.unasam.edu.pe/handle/UNASAM/3562

Medeiros, F., Soares, J., Neto, F., Caiana, C., Silva, E., \& Júnior, F. (2020). Teoria da derrotabilidade e seus efeitos sobre a escusa absolutória nos crimes patrimoniais. Research, Society and Development.

Noguera, R. (2020). Introducción general al derecho. http://repository.usergioarboleda.edu.co/handle/11232/1337

Orozco, J. (2020). La jurisprudencia sobre “casos límite” en materia de pensión de invalidez: Derrotabilidad normativa desde la Constitución. Prolegómenos: Derechos y valores, 23(45), 33-49. https://dialnet.unirioja.es/servlet/articulo?codigo=7442739

Pastor, L. (2019). Vulneración de la Dignidad de Persona Humana por Errores Judiciales en el Sistema Jurídico Peruano Tacna 2017 (maestría) Universidad privada de Tacna, Tacna. http://repositorio.upt.edu.pe/handle/UPT/

Pazos, M. (2002). Normas derrotables. Perspectivas y horizontes de la Filosofía de la Ciencia a la vuelta del nuevo milenio, 181-212. 
Pulido, F. (2018). Alcance y derrotabilidad de las reglas jurídicas. Problema anuario de filosofía y teoría del derecho de una revista partícipe del acervo de la Biblioteca Jurídica Virtual del Instituto de Investigaciones Jurídicas de la UNAM.

Ramírez, M. (2019). Técnicas de interpretación aplicada en la incompatibilidad normativa, proveniente de la sentencia de la Corte Suprema de Justicia, en el expediente $N^{\circ} 15163-2017$, del distrito judicial del Lima Este-Lima, 2018. http://repositorio.uladech.edu.pe/handle/123456789/11072

Rodríguez, E. (2014). El Tribunal Constitucional y el conflicto entre la libertad de información y los derechos al honor, la intimidad y la propia imagen: revisión jurisprudencial. Estudios sobre el Mensaje Periodístico, 20(2), 1209-1224.

https://revistas.ucm.es/index.php/ESMP/article/download/47061/44132

Rodríguez, R. (2015). Una teoría sobre la derrotabilidad jurídica en el Estado Constitucional. http://e-archivo.uc3m.es/handle/10016/22404

Ross, W. (1994). Lo correcto y lo bueno. Salamanca: Sígueme. http://www.sigueme.es/docs/libros/lo-correcto-y-lo-bueno-web.pdf

Ruiz, R. (2012). La distinción entre reglas y principios y sus implicaciones en la aplicación del derecho. Derecho y realidad, 10 (20).

https://revistas.uptc.edu.co/index.php/derecho realidad/article/download/4860/3952

Sacristán, E. (2017). El concepto de dignidad humana en la jurisprudencia de la Corte Suprema de Justicia de la Nación. https://repositorio.uca.edu.ar/handle/123456789/2776 